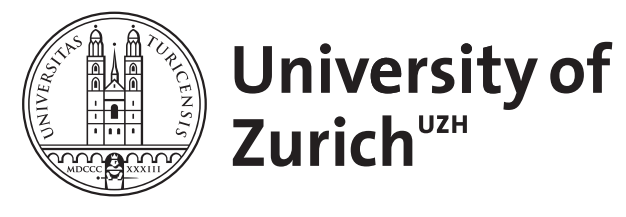

\title{
Sphenoid Sinus Epidermoid Cyst
}

Scheffel, Hans ; Wassermann, Veronica ; Pangalu, Athina ; Kollias, Spyros S

\begin{abstract}
We present an unusual case of an epidermoid cyst in the sphenoid sinus with extensive bony erosions and mass effect, compressing the optic nerve causing visual disturbances. Epidermoid cysts of the paranasal sinuses are extremely rare cases. They usually present as intradural, extraaxial, benign masses of the cerebellopontine angle but they should also be considered in the differential diagnosis of sphenoid sinus lesions. The typical imaging appearance of craniocerebral epidermoid cysts is demonstrated and pathophysiological considerations of formation in the paranasal sinuses are discussed
\end{abstract}

DOI: https://doi.org/10.1007/s00062-006-6032-y

Posted at the Zurich Open Repository and Archive, University of Zurich

ZORA URL: https://doi.org/10.5167/uzh-155943

Journal Article

Published Version

Originally published at:

Scheffel, Hans; Wassermann, Veronica; Pangalu, Athina; Kollias, Spyros S (2006). Sphenoid Sinus Epidermoid Cyst. Clinical Neuroradiology, 16(4):254-257.

DOI: https://doi.org/10.1007/s00062-006-6032-y 


\title{
Sphenoid Sinus Epidermoid Cyst
}

\author{
A Case Report
}

\author{
Hans Scheffel, Veronica Wassermann, Athina Pangalu, Spyros S. Kollias ${ }^{1}$
}

\begin{abstract}
We present an unusual case of an epidermoid cyst in the sphenoid sinus with extensive bony erosions and mass effect, compressing the optic nerve causing visual disturbances. Epidermoid cysts of the paranasal sinuses are extremely rare cases. They usually present as intradural, extraaxial, benign masses of the cerebellopontine angle but they should also be considered in the differential diagnosis of sphenoid sinus lesions. The typical imaging appearance of craniocerebral epidermoid cysts is demonstrated and pathophysiological considerations of formation in the paranasal sinuses are discussed.
\end{abstract}

Key Words: Sphenoid sinus · Epidermoid cyst · Diagnostic imaging

Clin Neuroradiol 2006;16:254-7

DOI 10.1007/s00062-006-6032-y

\section{Epidermoidzyste des Sinus sphenoidalis. Ein Fallbericht}

\section{Zusammenfassung}

Wir präsentieren einen Fall mit der ungewöhnlichen Lokalisation einer Epidermoidzyste im Sinus sphenoidalis mit ausgedehnten knöchernen Arosionen, Zeichen der Raumforderung und Kompression des Nervus opticus. Die Nasennebenhöhlen sind ein äußerst seltener Manifestationsort der Epidermoidzysten. Gewöhnlich zeigen sie sich als intradural und extraaxial gelegene benigne Raumforderungen des Kleinhirnbrückenwinkels. Sie sollten jedoch in die Differentialdiagnose der Läsionen des Sinus sphenoidalis eingeschlossen werden. Die charakteristische Bildgebung kraniozerebraler Epidermoidzysten wird demonstriert, und pathophysiologische Erklärungen zur Entstehung in den Nasennebenhöhlen werden diskutiert.

Schlüsselwörter: Sinus sphenoidalis · Epidermoidzyste · Diagnostische Neuroradiologie

\section{Introduction}

Epidermoid cysts can occur all over the human body and nearly $7 \%$ are located in the head and neck region [1]. They account for 0.2 to $1.8 \%$ of all primary intracranial tumors and usually present as intradural, extraaxial, benign masses of the cerebellopontine angle, parasellar or chiasmal regions [2]. Occipital or nasofrontal dermal sinus tracts are associated abnormalities [3] and malignant change is very rare [4]. Epidermoid cysts of the paranasal sinuses are rarely reported and, to our knowledge, only two cases have been described arising in the sphenoid sinus [5,6].

${ }^{1}$ Institute of Neuroradiology, University Hospital Zurich, Switzerland.

Submitted: July 20, 2006; Accepted: October 10, 2006 


\section{Case Report}

A 32-year-old female with neonatal blindness on the left eye experienced pain in the nasal region over ten days and progressive visual loss on the right eye over the last three days. Anamnesticly, she reported a similar episode two years ago. Ophthalmologic examination showed no light perception on the left eye and 40 to $60 \%$ visual loss on the right eye. The patient showed high grade hearing loss on the left ear with anamnestic chronic otitis media and dumbness on the right following ear surgery for cholesteatoma at the age of three. She had a clinical history of insulin-dependent diabetes mellitus. There was no history of head injury.

MRI was performed at a 3 Tesla MR system (Intera, Philips Medical Systems Best, The Netherlands) consisting of T1- and T2-weighted axial and coronal spin-echo series, and T1-weighted spin-echo series after intravenous administration of paramagnetic contrast agent in three planes. Spiral CT (Siemens Volume 4 Plus) before and after intravenous contrast administration was also performed, and the images were reconstructed in three orthogonal planes. A midline, homogeneous mass lesion was detected centered in the sphenoid sinus and extending to the ethmoid and nasal cavity as well as the frontal sinuses bilaterally. The frontal skull base was eroded without evidence of intracranial dural invasion (Figure 1a). Compression of the right optic nerve was

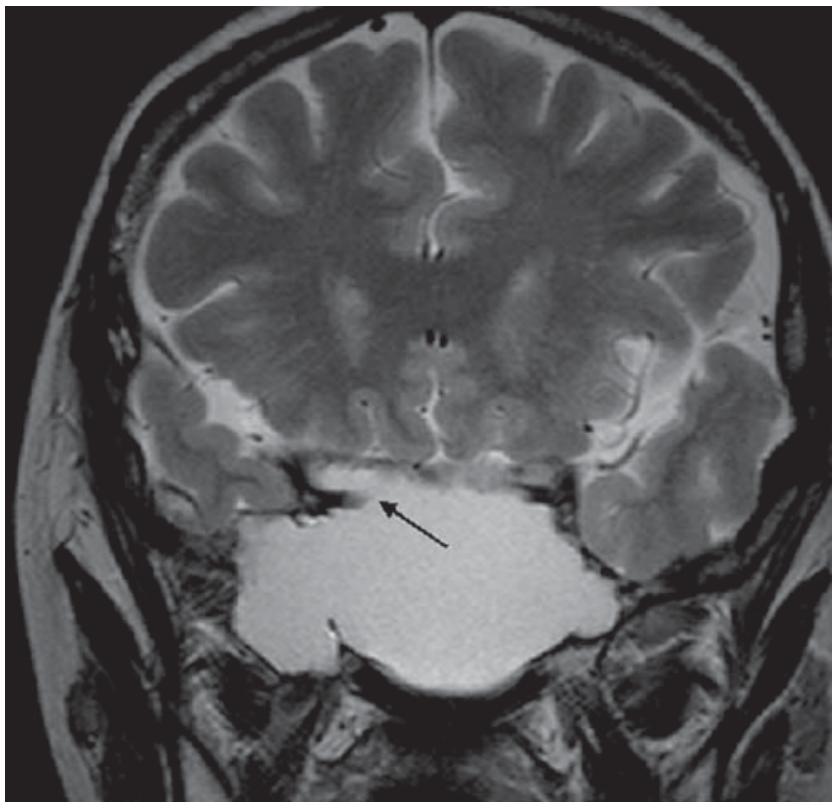

Figure $\mathbf{1 b}$. Coronal T2-weighted MR image shows extension of the cyst in the optic canal on the right side compressing the optic nerve (arrow). evident (Figure 1b). The tumor was hypodense on CT, and had prolonged $\mathrm{T} 1$ and $\mathrm{T} 2$ relaxation times on the MRI (Figure 1b and 1c.) A slight rim-enhancement was present on the post-contrast images (Figure 1c).

The patient was started on antibiotics and high-dose steroids. A bioptic transnasal resection of the mass was

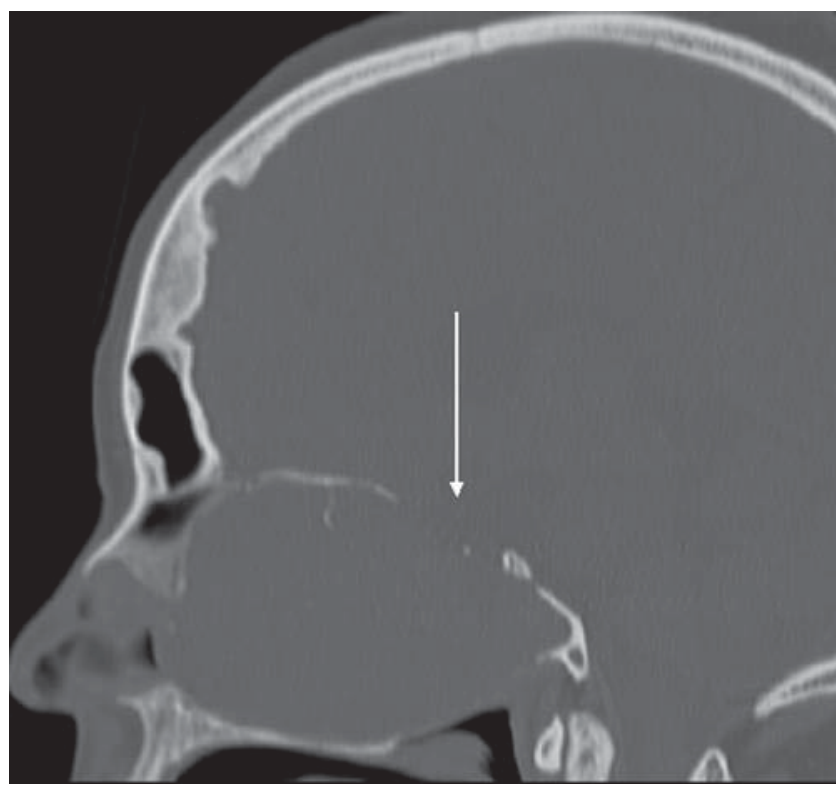

Figure 1a. Sagittal re-formatted bone windows CT image demonstrates erosion of the frontobasis (arrow).

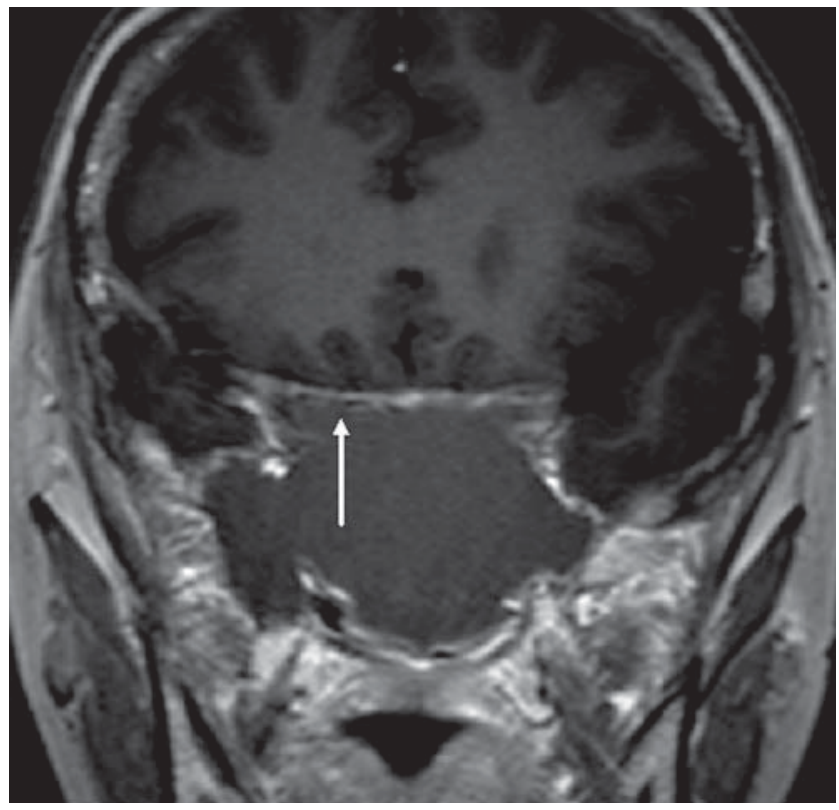

Figure 1c. Coronal T1-weighted MR image after intravenous contrast administration shows contrast enhancement in the periphery of the cyst (arrow). 


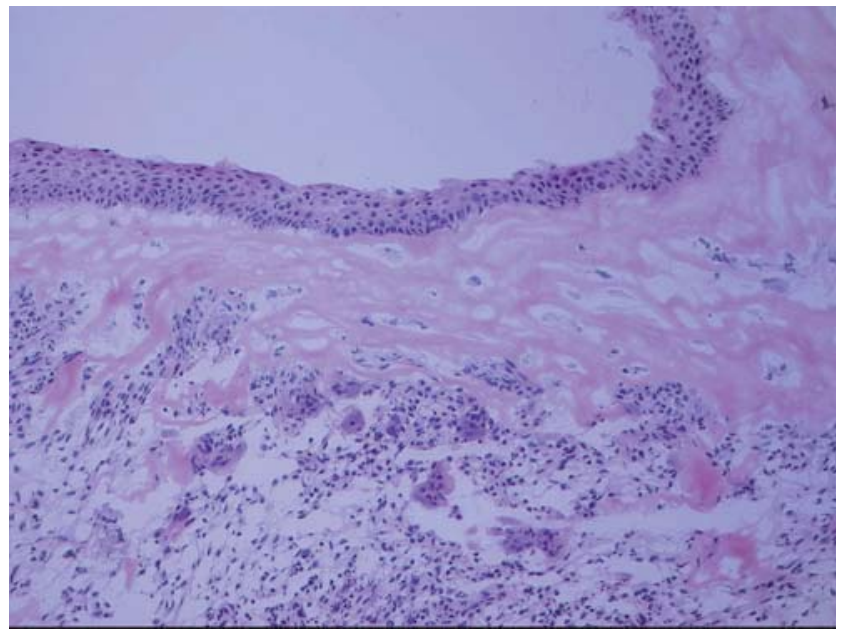

Figure 1d. Microscopic image stained with HE shows the epitheliallined cyst with surrounding inflammation.

performed three days later by the otorhinolaryngologists.

Histological examination revealed a squamous celllined cyst with chronic inflammation and fibrosis without signs of malignancy consistent with an epidermoid cyst (Figure 1d). The entire mass was removed together with the cyst wall via a transsphenoidal approach, which allowed a wide access to the mass through the anterior wall of the sinus. Intraoperatively, the sphenoid sinus was completely obliterated and the mass was causing erosion of the surrounding bone tissue, particularly of the sphenoid planum. The right optic nerve was compressed corresponding to the preoperative MR and CT images. Two hours following surgery there was a strong nasal bleeding followed by successful endoscopic intervention. In the following days there was an uneventful clinical course with improved vision on the right eye, and the patient left the hospital ten days after the admission.

\section{Discussion}

The occurrence of epidermoid cysts in the paranasal sinuses is rare. In reviewing the literature we found no previous description of an epidermoid cyst arising in the sphenoid sinus with erosion of the surrounding bony structures and expansion in the other paranasal sinuses and skull base. Clinical manifestation of this entity with symptoms of optic nerve compression has also not been previously described. Individual cases with lesser extent and isolated involvement of the sphenoid sinus have been previously reported [5,6]. A recently published case report shows an epidermoid cyst of the sphenoid sinus with extension into the sella turcica presenting as pituitary apoplexy [6].

Craniocerebral congenital epidermoid cysts are thought to arise from inclusion of ectodermal epithelial elements at the time of neural tube closure between the third and fifth week of embryonic life [3]. Several pathogenetic mechanisms are implicated in the formation of intradiploic epidermoid cysts of the skull including congenital origin, metaplasia or traumatic etiology [7]. Congenital entrapment of ectodermal elements within the fusion plates between chondrification centers of the alisphenoid and presphenoid bones during embryogenesis could result in formation of an intradiploic epidermoid cyst of the sphenoid bone or the sphenoid sinus, which is intradiploic in itself. Metaplasia of the ciliated respiratory epithelium of the paranasal sinuses towards squamous epithelium may occur as a result of altered pneumatization of the sinus due to chronic inflammation or an infection. Finally, trauma with deposition of squamous epithelium within the bone is the third possible pathogenesis for the development of an intrasinal epidermoid cyst. In our case there is neither history of head trauma nor of chronic sinusitis; therefore, the most possible pathogenesis is of congenital origin.

Epidermoid cysts of the cranial bones can grow to very large size as in our case before becoming symptomatic. They have a slow, but relentless, growth and sometimes these lesions are incidental findings. A variety of neurologic symptoms are possible depending on the location where the remnants are trapped. When the paranasal sinuses are involved, the cysts can become infected. Their local destructive capacity as shown in our case is well recognized and described in the literature. Because of their propensity to grow continuously, it is recommended to treat them surgically when diagnosed. The cystic lesion should be completely removed together with its capsule to avoid recurrence [8].

CT imaging was very useful to precisely assess the extent of bone erosion by the lesion, particularly the involvement of the skull base. MRI better demonstrated the relationship of the cyst to the nerve structures, which is typical for epidermoid cysts [9]. In our case the relation to the optic nerve was of clinical relevance for the outcome of the patient. Typical MRI findings of an epidermoid cyst are of a homogeneous lesion with signal intensities similar to cerebrospinal fluid (CSF) on both T1- and T2-weighted images. It may also be slightly hyperintense to CSF on T1-W images. Diffusion-weighted 
MR imaging (DWI), which was unfortunately not part of the imaging protocol in our case, has been proposed to help in differentiating epidermoid cysts from other lesions [10]. The solid nature of epidermoid cysts shows hyperintense signal characteristics in contrast to CSF containing cavities like arachnoidal cysts [11]. Furthermore a recent study showed that DWI is superior to conventional MR imaging in evaluating epidermoid cysts [2]. Although DWI of tumors of the paranasal sinuses and the adjacent skull base is prone to be hampered by artifacts, it provides useful information in differentiating benign from malignant tumors [12]. Therefore DWI should be part of the imaging protocol in these lesions. However, CT and MR imaging modalities are converging tools in differential diagnostic considerations. On CT the epidermoid cysts are hypodense and show no enhancement after intravenous contrast administration, although a slight rim enhancement may be present in some cases [13]. In rare situations epidermoid cysts can appear hyperintense on T1-weighted MR images and hyperdense on CT caused by high rate of protein concentration within the cyst [14]. These entities are not easily distinguished from a dermoid cysts or a mucocele, and other lesions like eosinophilic or cholesterol granuloma or an aneurysmal bone cyst [15-17], although rare in this location, may also be considered. The homogeneous consistency, sharp definition, and erosive rather than destructive appearance of these lesions, as well as the absence of contrast enhancement make differentiation from a carcinoma easy.

In conclusion, epidermoid cysts of the paranasal sinuses are rare but they should be taken into differential diagnostic thinking. Their conventional CT and MRI appearance including DWI helps in the differential diagnosis and provides accurate information for planning complete resection, which is the treatment of choice.

\section{References}

1. Turetschek K, Hospodka H, Steiner E. Case report: epidermoid cyst of the floor of the mouth: diagnostic imaging by sonography, computed tomography and magnetic resonance imaging. Br J Radiol 1995; 68:205-7.

2. Hakyemez B, Aksoy U, Yildiz H, Ergin N. Intracranial epidermoid cysts: diffusion-weighted, FLAIR and conventional MR findings. Eur J Radiol $2005 ; 54: 214-20$.
3. Osborn A. Diagnostic Imaging: I 7 Brain. Amirsys, Salt Lake City, Utah 2004 pp.16-9.

4. Hoeffel C, Heldt N, Chelle C, Claudon M, Hoeffel JC. Malignant change in an intradiploic epidermoid cyst. Acta Neurol Belg 1997;97:45-9.

5. Ohta S, Nishizawa S, Ryu H, Yokoyama T, Hinokuma K, Yamaguchi M, Uemura K. Epidermoid tumor in the sphenoid sinus - case report. Neurol Med Chir (Tokyo) 1997;37:350-3.

6. Sani S, Smith A, Leppla DC, Ilangovan S, Glick R. Epidermoid cyst of the sphenoid sinus with extension into the sella turcica presenting as pituitary apoplexy: case report. Surg Neurol 2005;63:394-7.

7. Bejarano PA, Broderick DF, Gado MH. Infected epidermoid cyst of the sphenoid bone. AJNR Am J Neuroradiol, 1993;14:771-3.

8. Wax MK, Briant TD. Epidermoid cysts of the cranial bones. Head Neck 1992;14:293-6.

9. Ulrich J. Intracranial Epidermoids. A study on their distribution and spread. J Neurosurg 1964:21:1051-8.

10. Annet L, Duprez T, Grandin C, Dooms G, Collard A, Cosnard G. Apparent diffusion coefficient measurements within intracranial epidermoid cysts in six patients. Neuroradiology 2002;44:326-8.

11. Dutt SN, Mirza S, Chavda SV, Irving RM. Radiologic differentiation of intracranial epidermoids from arachnoid cysts. Otol Neurotol 2002; 23:84-92.

12. White ML, Zhang Y, Robinson RA. Evaluating tumors and tumorlike lesions of the nasal cavity, the paranasal sinuses, and the adjacent skull base with diffusion-weighted MRI. J Comput Assist Tomogr 2006; 30:490-5.

13. Kallmes DF, Provenzale JM, Cloft HJ, McClendon RE. Typical and atypical MR imaging features of intracranial epidermoid tumors. AJR Am J Roentgenol 1997;169:883-7.

14. Timmer FA, Sluzewski M, Treskes M, van Rooij WJ, Teepen JL, Wijnalda D. Chemical analysis of an epidermoid cyst with unusual CT and MR characteristics. AJNR Am J Neuroradiol 1998;19:1111-2.

15. Bonneville F, Cattin F, Marsot-Dupuch K, Dormono D, Bonneville JF, Chiras J. T1 signal hyperintensity in the sellar region: spectrum of findings. Radiographics 2006;26:93-113.

16. Sampson JH, Rossitch E Jr, Young JN, Lane KL, Friedman AH. Solitary eosinophilic granuloma invading the clivus of an adult: case report. Neurosurgery 1992;31:755-7; discussion 757-8.

17. Gan YC, Mathew B, Salvage D, Crooks D. Aneurysmal bone cyst of the sphenoid sinus. Br J Neurosurg 2001;15:51-4.
Address for Correspondence
Hans Scheffel, MD
Institute of Neuroradiology
University Hospital Zürich
Frauenklinikstr. 10
$\mathrm{CH}-8091$ Zürich, Switzerland
Phone (+41/1) 255-1111, Fax -4443
e-mail:Hans.Scheffel@usz.ch 